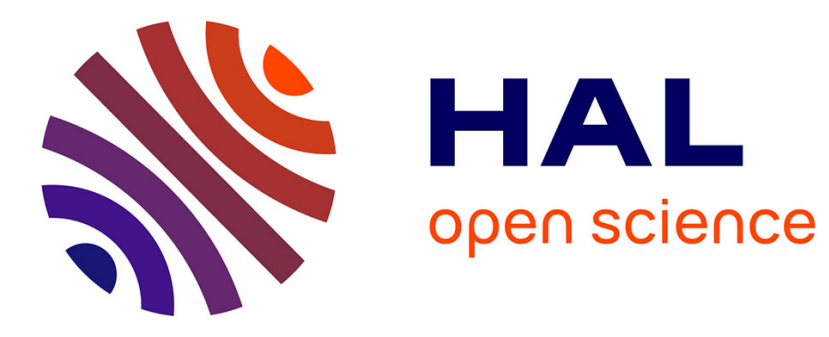

\title{
Modulation of the crystallinity of hydrogenated nitrogen-rich graphitic carbon nitrides
}

Denis Foy, Gérard Demazeau, Pierre Florian, Dominique Massiot, Christine Labrugère, Graziella Goglio

\section{- To cite this version:}

Denis Foy, Gérard Demazeau, Pierre Florian, Dominique Massiot, Christine Labrugère, et al.. Modulation of the crystallinity of hydrogenated nitrogen-rich graphitic carbon nitrides. Journal of Solid State Chemistry, 2009, 182 (1), pp.165-171. 10.1016/j.jssc.2008.10.018 . hal-00351466

\section{HAL Id: hal-00351466 https://hal.science/hal-00351466}

Submitted on 7 Apr 2009

HAL is a multi-disciplinary open access archive for the deposit and dissemination of scientific research documents, whether they are published or not. The documents may come from teaching and research institutions in France or abroad, or from public or private research centers.
L'archive ouverte pluridisciplinaire HAL, est destinée au dépôt et à la diffusion de documents scientifiques de niveau recherche, publiés ou non, émanant des établissements d'enseignement et de recherche français ou étrangers, des laboratoires publics ou privés. 


\section{Modulation of the crystallinity of hydrogenated nitrogen-rich graphitic carbon nitrides}

Denis FOY a, Gérard DEMAZEAU ${ }^{a}$, Pierre FLORIAN ${ }^{b}$, Dominique MASSIOT ${ }^{b}$, Christine LABRUGERE ${ }^{a, c}$, Graziella GOGLIO ${ }^{\mathrm{a}, *}$

${ }^{a}$ CNRS, Université Bordeaux, ICMCB, 87 avenue du Dr. A. Schweitzer, 33608 Pessac, France

${ }^{\mathrm{b}}$ CNRS UPR3079, CEMHTI, Université d'Orléans, 1D avenue de la recherche scientifique, 45071 Orléans cedex, France

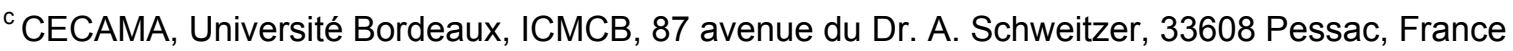

email addresses :

foy@icmcb-bordeaux.cnrs.fr; ～demazeau@icmcb-bordeaux.cnrs.fr; $\quad$ florian@cnrs-orleans.fr; massiot@cnrs-orleans.fr; labrugere@icmcb-bordeaux.cnrs.fr; goglio@icmcb-bordeaux.cnrs.fr

* Corresponding author :

Graziella GOGLIO

goglio@icmcb-bordeaux.cnrs.fr

Fax: +33 540002761 


\section{Abstract}

An hydrogenated nitrogen-rich graphitic carbon nitride, structurally related to the theoretical graphitic phase of $\mathrm{C}_{3} \mathrm{~N}_{4}$, has been synthesized in a bulk wellcrystallized form. This new material was prepared by thermal decomposition of thiosemicarbazide up to $600^{\circ} \mathrm{C}$ at ambient pressure under nitrogen flow. Its composition was determined by elemental combustion analysis. Powder X-ray diffraction, infrared spectroscopy, thermogravimetric analysis, X-ray photoelectron spectroscopy and $\mathrm{C}^{13}$ MAS NMR characterizations were performed. This material can be schematically described with a two-dimensional framework and a composition close to $\mathrm{C}_{3} \mathrm{~N}_{4.17} \mathrm{H}_{1.12}$. In this nitrogen-rich material, $\mathrm{C}_{3} \mathrm{~N}_{3}$ voids are fully occupied by water molecules which are strongly trapped into the material. A loss of crystallinity associated with a modification of the thermal behaviour is observed when the amount of trapped molecules decreases in the graphitic material, order being damaged both between and in the graphitic planes.

\section{Keywords}

carbon nitride; graphitic materials; X-ray diffraction (XRD), Nuclear Magnetic Resonance (NMR); X-ray photoelectron spectroscopy (XPS); Thermogravimetric analysis (TGA); Triazine; Heptazine 


\section{Introduction}

Light element-based materials are of great interest owing to their specific physicochemical properties (particularly hardness) mainly due to the strong covalency of the chemical bonds and to the three-dimensional character of the different structures they can adopt [1]. In this way, dense (3D) polymorphs with $\mathrm{C}_{3} \mathrm{~N}_{4}$ composition were predicted to present very low compressibility and superharness [2-7]. More generally, it was claimed that $\mathrm{C}_{3} \mathrm{~N}_{4}$ stoichiometry was not necessary to observe exceptional mechanical properties in carbon nitrides, the inescapable condition being the three-dimensionality of the atomic framework [8-9]. Until now many attempts were made to synthesize these 3D hypothetical carbon nitrides by means of various techniques either as bulk materials [9] or thin films [10]. Nevertheless they mainly led to the formation of amorphous or poorly crystallized non-stoichiometric materials or to small crystallites embedded in an amorphous matrix. Despite these direct elaboration processes, the elaboration of lowcompressibility carbon nitrides can be issued from a conversion process. In this case, flux assisted conversion processes developed in case of diamond and cubic boron nitride synthesis could be performed, a low density variety being then needed as a precursor [11]. In this way, graphitic (2D) carbon nitrides can be considered as adequate candidates. Various 2D forms were theoretically suggested with either hexagonal or orthorhombic cells and different stackings of the graphene planes $[4,7,12-13]$. In these materials carbon is fully involved in $\mathrm{C}_{3} \mathrm{~N}_{3}$ heterocycles, these triazine rings being bridged one to another by $\mathrm{N}-\mathrm{C}$ bonds. This bonding nitrogen belongs or not to the cycles, depending on the model. Recently, several structural models based on the heptazine (tri-s-triazine) unit were also 
proposed [14]. These graphitic materials derivated from the melon polymer are claimed more stable than their homologous with triazine units. So far graphitic carbon nitrides were widely elaborated. Whatever experimental conditions, it was evidenced that the $\mathrm{C} / \mathrm{N}$ molar ratio was difficult to control as well as crystallinity which was often poor. All materials were also significantly hydrogenated. It was proposed that $\mathrm{C} / \mathrm{N}$ molar ratios lower than 0.75 could be explained in terms of $\mathrm{C}_{3} \mathrm{~N}_{3}$ triazine voids into the graphenes planes, which did not seem to affect drastically the thermal stability of the materials [9]. It appears important to understand then how crystallinity can be modulated in graphitic carbon nitrides because it will influence the conversion process, as well as additive elements such as hydrogen will do.

We report here the original synthesis of a well-crystallized graphitic nitrogen-rich carbon nitride by thermal decomposition of an organic reagent. A special care was given to investigate carbon and nitrogen environments. A sulfur treatment during the thermal process allowed us to modulate the composition of the material, hydrogen and oxygen amounts being strongly influenced while the carbon-nitrogen network was unchanged. We discuss here the consequences of such evolutions on the crystallinity of the material.

\section{Experimental}

\subsection{Raw-sample preparation}

In the typical procedure, 2 grams of thiosemicarbazide $\left(\mathrm{CH}_{5} \mathrm{~N}_{3} \mathrm{~S}\right.$ Aldrich, 99\%) were placed in a Pyrex boat, this manipulation being performed in a glove-box with flowing nitrogen gas because the organic reagent is hygroscopic. The tube was maintained during any transport under $\mathrm{N}_{2}$ atmospher and was introduced in a 
tubular furnace under nitrogen flow. Temperature was slowly increased $\left(1^{\circ} \mathrm{C} / \mathrm{min}\right)$ up to several consecutive intermediate $1 \mathrm{~h}$ steps at $180,250,350$ and $480^{\circ} \mathrm{C}$ and then finally maintained at $600{ }^{\circ} \mathrm{C}$ for $10 \mathrm{~h}$. Then the sample was cooled down to room temperature (RT) naturally. The as-obtained orange powder is called rawsample.

\subsection{Modification of the chemical composition}

We performed previous experiments by thermogravimetric analysis coupled with mass spectroscopy. We observed that during the thermal decomposition of thiosemicarbazide under $\mathrm{N}_{2}$ atmosphere, a large part of sulfur departure from the material occurred below $300^{\circ} \mathrm{C}$ leading to the formation of $\mathrm{H}_{2} \mathrm{~S}$ gaseous species. We then considered that adding sulfur below $300^{\circ} \mathrm{C}$ would enhance $\mathrm{H}_{2} \mathrm{~S}$ formation during the decomposition process and then decrease residual hydrogen amount in the as-obtained material.

As a consequence, thiosemicarbazide was heated as mentioned above up to $180^{\circ} \mathrm{C}$ then cooled to RT naturally. Sulfur was then intimately mixed with the resulting product in a molar ratio sulfur/thiosemicarbazide (taking here into account the initial amount of $\mathrm{CH}_{5} \mathrm{~N}_{3} \mathrm{~S}$ ) equal to 2.2. The mixture was then placed in the Pyrex boat, introduced in the tubular furnace and submitted to the end of the thermal decomposition procedure (i.e. $1 \mathrm{~h}$ steps at 250,350 and $480{ }^{\circ} \mathrm{C}, 10 \mathrm{~h}$ step at $600{ }^{\circ} \mathrm{C}$, then cooling at RT). The as-obtained sample is called 180 -sample.

Finally, 250-sample was obtained according to the same principle, sulfur being here added in the same amount after the $250{ }^{\circ} \mathrm{C}$ step.

180-sample and 250-sample are powdered materials which exhibit the same orange colour than raw-sample. 


\subsection{Samples characterization}

X-ray diffraction (XRD) patterns were collected on a PANalytical X'Pert MPD X-ray diffractometer with $\mathrm{Cu} \mathrm{K} \alpha$ radiation $(\lambda=1.5418 \AA$ ). Infrared (IR) spectra were recorded on a IR Paragon 1000 spectrophotometer pelleting the sample with $\mathrm{KBr}$. Bulk elemental combustion analysis of $\mathrm{C}, \mathrm{H}, \mathrm{N}, \mathrm{O}, \mathrm{S}$ elements was performed on a Thermofisher Flash EA 112 analyzer. Thermogravimetric analysis was performed with a SETARAM TAG 2400 equipment using a platinum crucible under argon flow (50 mL/min). A coupling with THERMOSTAR mass spectrometer was used. Rawsample was characterized by X-ray photoelectron spectroscopy (XPS) on a VG 220i-XL ESCALAB spectrometer equipped with a non-monochromatized AIK $\alpha$ source. The analyzed area was about $250 \mu \mathrm{m}$ in diameter. The pressure in the chamber was in the range of $10^{-7} \mathrm{~Pa}$. The spectra were fitted using the AVANTAGE program provided by THERMOFISHER SCIENTIFIC. ${ }^{13} \mathrm{C}$ CPMAS NMR spectrum of raw-sample powder was recorded using a Bruker Avance $300 \mathrm{MHz}$ spectrometer under a 7.0 T magnetic field with a magic angle rotation at $10 \mathrm{KHz}$. The ${ }^{1} \mathrm{H}$ MAS NMR spectrum was recorded on the same apparatus with a magic angle rotation at $8 \mathrm{KHz}$ and a Hahn echo pulse sequence (short Hahn echo time of $300 \mu \mathrm{s})$. The ${ }^{13} \mathrm{C}$ and ${ }^{1} \mathrm{H}$ chemical shifts were referenced to tetramethylsilane at 0 ppm.

\section{Results and discussion}

\subsection{Characterization of raw-sample}

Elemental combustion analysis of raw-sample confirms that the material is a carbon nitride (General formula in Table I). The $\mathrm{C} / \mathrm{N}$ molar ratio $(0.72)$ indicates a 
slight overstoichiometry in nitrogen. Although nitrogen deficiency is common in carbon nitrides because of the stability of the easily-formed $\mathrm{N}_{2}$ molecules, it was evidenced that mild experimental conditions involved in processes such as solvothermal reactions or thermal decomposition are favorable to retain nitrogen in the material, leading then to nitrogen-rich materials $[9,15-18]$. The presence of hydrogen in raw-sample is not surprising as it is usually evidenced in carbon nitrides [9,15-16,19-23]. Finally, the presence of oxygen, although in low content, should be noticed as well as the absence of sulfur in raw-sample.

Thermogravimetric analysis was then performed on raw-sample in order to evaluate its thermal stability. The as-obtained TGA curve (Fig. 1a) firstly exhibits mass loss below $180^{\circ} \mathrm{C}$ which consists in $2.4 \mathrm{w} \%$ and is assessed to water removing according to mass spectroscopy results (no other species is detected on mass spectrum during this first water departure). Considering the adsorbed water amount, we have calculated the composition of "dry" material (id est the composition after removing adsorbed water). The results presented in Table I (formula of "dry" materials + adsorbed water) evidence the significant presence of residual hydrogen and oxygen in the dry material that will be discussed in the next paragraph. Raw-sample undergoes a mass loss since $420^{\circ} \mathrm{C}$ with a decomposition temperature at $665^{\circ} \mathrm{C}$, this temperature being measured at the maximum of the derivative of the TGA curve. The thermal $\mathrm{H}_{2} \mathrm{O}$ evolution curve deduced from mass spectrometry measurements presented on the inset a) of Fig. 1 clearly shows that during this final decomposition a second water departure is observed. Raw-sample is fully decomposed at $690^{\circ} \mathrm{C}$, which is comparable with previous values claimed in literature concerning thermal decomposition of graphitic carbon nitrides 
$[15,20,22,24-25]$. In these materials, the good thermal stability is thought to be provided by triazine or heptazine rings.

Fig. 2a shows the XRD pattern of raw-sample. It is similar to those of graphitic-like carbon nitrides as it is characterized by a strong reflection peak centered at $3.24 \AA$ $[15-20,22,26,29]$. This peak is reminiscent of the $\left(\begin{array}{lll}0 & 0\end{array}\right)$ basal reflection plane in graphite that occurs at $3.32 \AA$. Its short full width at half maximum value $(\mathrm{FWHM}=$ $\left.1.4^{\circ}, 2 \theta\right)$ and the presence of the $\left(\begin{array}{lll}0 & 0 & 4\end{array}\right)$ reflection centred at about $1.6 \AA$ suggest a well-ordered stacking of the graphene planes along the c-axis. Three other peaks with weaker intensities appear on the XRD pattern at $6.8 \AA, 5.0 \AA$ and 4.1 $\AA$. As these peaks can not be assigned to $(0 \mathrm{O} /)$ reflections, they reveal order into the graphene planes, id est in the a-b dimension. This XRD pattern of raw-sample is then consistent with that of a well crystallized carbon nitride.

Additional characterization of this graphitic carbon nitride and investigation on the hydrogen location were provided by IR spectroscopy. The IR spectrum of rawsample (Fig. 3a) is classical of that observed for graphitic carbon nitrides [1517,20-22,27-28,30-37]. The absorptions between 1100 and $1700 \mathrm{~cm}^{-1}$ are typical for molecules that contain $\mathrm{CN}$ heterocycles (stretching vibrations of triazine ring). The sharp absorption at $800 \mathrm{~cm}^{-1}$ belongs to deformation of s-triazine or tri-striazine rings, which then gives evidence for the existence of $\mathrm{C}_{3} \mathrm{~N}_{3}$ cycles in the material as expected in graphitic carbon nitrides. The broad absorption band at $3100 \mathrm{~cm}^{-1}$ is related to modes involving $\mathrm{N}-\mathrm{H}$ stretching vibrations. As ever mentioned by Kawaguchi and Nozaki [19], it is probable that hydrogen is bonded to nitrogen atoms which do not belong to triazine ring but which are preferably outside the ring (bridging nitrogen). This IR characterization then precises the location of hydrogen in the material and, due to the absence of absorption at 2800 
$\mathrm{cm}^{-1}$, the existence of bonds between carbon and hydrogen tends to be excluded [38]. Finally the slight asymetry at $3350 \mathrm{~cm}^{-1}$ can be attributed to $\mathrm{O}-\mathrm{H}$ vibrations, which is consistent with the presence of water in the material.

X-ray photoelectron spectroscopy (XPS) study was then investigated on rawsample in order to extract information concerning the chemical nature of bonds. The XPS C1s spectrum was analyzed using three components (Fig. 4a). The main one is centered at $288.0 \mathrm{eV}$ and corresponds to $\mathrm{sp}^{2} \mathrm{C}$ atoms involved in $\mathrm{C}_{3} \mathrm{~N}_{3}$ triazine cycles, the contribution at $284.8 \mathrm{eV}$ is attributed to $\mathrm{C}-\mathrm{C}$ bond from carbon contamination, the component at $293.2 \mathrm{eV}$ corresponds to the $\pi$ electrons delocalization in $\mathrm{C}_{3} \mathrm{~N}_{3}$ heterocycles [18,28,39-41]. While in raw-sample, carbon is only involved in triazine cycles, the XPS N1s spectrum appears much more complex as it can be analyzed on the basis of four components suggesting then an variety of nitrogen environments as shown on Fig. 4b $[19,23,28,40,42]$. The main component is centered at $398.3 \mathrm{eV}$ and is attributed to $\mathrm{sp}^{2} \mathrm{~N}$ involved in $\mathrm{C}_{3} \mathrm{~N}_{3}$ cycles, the $\pi$ electrons delocalization in $\mathrm{C}_{3} \mathrm{~N}_{3}$ heterocycles leading to a peak at $404.1 \mathrm{eV}$. The contribution at $399.9 \mathrm{eV}$ corresponds to bridging nitrogen atoms such as $\mathrm{N}\left(\mathrm{C}_{3} \mathrm{~N}_{3}\right)_{3}$ or $\mathrm{NH}\left(\mathrm{C}_{3} \mathrm{~N}_{3}\right)_{2}$ or $\mathrm{NH}_{2}\left(\mathrm{C}_{3} \mathrm{~N}_{3}\right)$ as ever mentioned by Kawaguchi and Nozaki [19]. The last peak at $400.9 \mathrm{eV}$ is thought to originate from surface pollution ( $\mathrm{N}-(\mathrm{CO}))$; in our case no sputtering was used to clean the powder surface because it has been shown that this high energy process results in preferential nitrogen loss and changes in nitrogen chemical environment [15]. In this material, it then seems obvious that nitrogen can adopt two main surroundings whether it is involved in triazine cycles or not. One should notice that the two main contributions evidenced on N 1s XPS spectrum are in agreement with those observed in case of melamine [21]. Calculating the ratio of the areas of the peaks at 399.9 and 398.3 
$\mathrm{eV}$, we obtain the atomic ratio of the two corresponding species, respectively. The obtained value of 0.3 indicates that the number of nitrogen atoms belonging to cycles is roughly three times the number of nitrogen atoms bridging them. This result is fully consistent with structural considerations on nitrogen surroundings in theoretical graphitic carbon nitride according to Teter and Hemley's model [7].

A sharper description of carbon environment in raw-sample has been investigated by NMR. The ${ }^{13} \mathrm{C}$ CPMAS (ramp cross polarization) spectra show two well separated lines at $164 \mathrm{ppm}\left(\Delta v_{1 / 2} \sim 4.0 \mathrm{ppm}\right)$ and $157 \mathrm{ppm}\left(\Delta v_{1 / 2} \sim 3.5 \mathrm{ppm}\right)$ with very different cross polarization behaviour as evidenced on Fig.5. These chemical shifts are in agreement with values for $\mathrm{sp}^{2}$ carbon atom involved in $\mathrm{C}_{3} \mathrm{~N}_{3}$ cycles. However the existence of two chemically different types of carbon atoms with different distances from $\mathrm{H}$ can not be explained within the $\mathrm{C}_{3} \mathrm{~N}_{4}$ graphitic network described by Teter and Hemley [7] as in this case carbon adopts a unique environment, the signal being expected at $150 \mathrm{ppm}$. The dominant contribution is the $164 \mathrm{ppm}$ line at small contact times $(1 \mathrm{~ms})$ and the $157 \mathrm{ppm}$ line at larger contact times ( $7 \mathrm{~ms}$ for the spectrum showed in Fig. 5). This behaviour evidences a significant contrast in ${ }^{1} \mathrm{H} /{ }^{13} \mathrm{C}$ dipolar interaction and thus $\mathrm{H}-\mathrm{C}$ distances between the two types of sites, making it difficult to deduce quantitative interpretation of CPMAS spectra as remarked by Zhang et al. [16]. The proton $\left({ }^{1} \mathrm{H}\right)$ MAS spectrum presented on figure 6 shows a dominant contribution at $\sim 10 \mathrm{ppm}$ in the typical range of amine protons in the solid state, which is the source of the transferred ${ }^{13} \mathrm{C}$ magnetization of the CPMAS experiment as testified by a two dimensional $\left\{{ }^{1} \mathrm{H}\right\}{ }^{13} \mathrm{C}$ experiment. Lines at chemical shifts of typically 150 to $159 \mathrm{ppm}$ have been reported from MAS and mostly CPMAS experiments for $\mathrm{CN}_{3}$ environments in bulk carbon nitrides $[24,39,41]$ while lines at 163 to $166 \mathrm{ppm}$ where repeatedly 
evidenced in protonated molecular compounds (such as $\mathrm{C}_{6} \mathrm{~N}_{9} \mathrm{H}_{3} . \mathrm{HCl}$ [16]) or in complex systems $[39,41])$. Recent work combining NMR and ab-initio computation [43] has proposed the attribution of $\mathrm{CN}_{3}$ bulk component to the $\sim 157 \mathrm{ppm}$ contribution and of $\mathrm{CN}_{2}\left(\mathrm{NH}_{\mathrm{x}}\right)$ environment to the 163-165 ppm contribution. Our results are in full agreement with this assignment, in particular with the chemical shift of the ${ }^{1} \mathrm{H}$ spectrum and with the higher cross dipolar interaction (polarisation efficiency) for $\mathrm{CN}_{2}\left(\mathrm{NH}_{\mathrm{x}}\right)$ carbons as compared to $\mathrm{CN}_{3}$ motifs.

\subsection{Influence of sulfur addition during thermal decomposition}

180-sample and 250-sample both adopt quite the same chemical composition which is different from that of raw-sample as presented in Table I (general formula). For materials obtained after sulfur addition, the $\mathrm{C} / \mathrm{N}$ molar ratio remains unchanged while hydrogen and oxygen contents are considerably increased. It should be noticed that, for both materials, no sulfur is detected during elemental chemical analysis.

According to TGA measurements, adsorbed water departure (which has been identified by mass spectrometry as presented on the inset c) of Fig. 1 for 250sample, no other species being detected during this first water departure) involves 13.6 w\% mass losses for 180-sample and 250-sample (Fig.1b and 1c, respectively). This mass loss begins at room temperature during vacuum before increasing temperature. Results presented in Table I (formula of "dry" materials + adsorbed water) evidence that, whatever the temperature of sulfur addition, this sulfur treatment involves an important increase of adsorbed water $\left(\mathrm{H}_{2} \mathrm{O}_{a d s}\right)$ and the decrease of hydrogen and oxygen residual amounts in "dry" samples, which can be roughly associated to the loss of $0.16 \mathrm{H}_{2} \mathrm{O}$ per "dry" sample formula. As a 
consequence, it is reasonable to consider that residual oxygen and some hydrogen in the "dry" samples arise from water molecules which are trapped in the structure (they will be called here "bonded water" $\mathrm{H}_{2} \mathrm{O}_{\text {bond }}$ ), contrary to adsorbed water molecules $\mathrm{H}_{2} \mathrm{O}_{a d s}$ which can be easily evacuated. This hypothesis is supported by the observation of several water releases above $250^{\circ} \mathrm{C}$ during continuous decomposition of 250-sample as seen on inset c) on Fig.1. In this way, if we schematically consider that all oxygen atoms of "dry" samples are involved in $\mathrm{H}_{2} \mathrm{O}_{\text {bond }}$ (neither $\mathrm{C}-\mathrm{O}$ nor $\mathrm{N}-\mathrm{O}$ bonds being detected in three samples by infrared spectroscopy, then oxygen is not involved in the carbon nitride skeleton), we can deduce detailed formula for three "dry" samples as mentioned in Table I.

It is then interesting to notice that, while sulfur drastically affects $\mathrm{H}_{2} \mathrm{O}_{\text {bond }}$ content, it has no significant effect on the hydrogenated carbon nitride network which $\mathrm{C}_{3} \mathrm{~N}_{4.2} \mathrm{H}_{1.1}$ composition is maintained. The addition of sulfur during the process decomposition probably induces the formation of gazeous species such as $\mathrm{H}_{2} \mathrm{~S}$ and $\mathrm{SO}_{2}$ (with standard enthalpies of formation of -33.4 and $-300 \mathrm{KJ} . \mathrm{mol}^{-1}$, respectively [44]) by reaction with hydrogen and oxygen giving then rise to a decrease of $\mathrm{H}_{2} \mathrm{O}_{\text {bond }}$, resulting materials being highly hygroscopic (which induces a great increase of $\mathrm{H}_{2} \mathrm{O}_{a d s}$ ).

Contrary to raw-sample, no stability domain is observed after adsorbed water departure for 180-sample and 250-sample, decomposition being quite continuous (Fig. $1 \mathrm{~b}$ and 1c, respectively). Both samples exhibit comparable thermal behaviours. Nevertheless, the decomposition temperature remains constant for three samples $\left(665^{\circ} \mathrm{C}\right), 180$-sample and 250 -sample being totally decomposed at 700 and $706^{\circ} \mathrm{C}$, respectively. 
When compared with raw-sample, crystallinity of 180 -sample and 250 -sample is considerably damaged as evidenced by XRD patterns presented on Fig. $2 \mathrm{~b}$ and 2c. Here, while its position is unchanged, the main peak gets broader (FWHM =3.1 and $3.3^{\circ}$ for 180 -sample and 250 -sample, respectively) and the reflections at lower angles have disappeared. When sulfur is involved during thermal decomposition of thiosemicarbazide, a partial amorphization occurs, order being damaged in the asobtained graphitic materials both into the planes and along their staking direction. The XRD pattern of dried 180-sample $\left(\mathrm{H}_{2} \mathrm{O}_{a d s}\right.$ was removed from material by thermal treatment under vacuum at $120^{\circ} \mathrm{C}$ during $1.5 \mathrm{hr}$, a $13.5 \%$ weight loss being then measured) evidences that adsorbed water is not responsible for this alteration of crystallinity as evidenced when comparing Fig.2d and $2 \mathrm{e}$.

Concerning 180-sample and 250-sample, the IR spectra shown on Fig. 3b and 3c, respectively, are similar to that obtained for raw-sample despite the clear appearance of an absorption at $3350 \mathrm{~cm}^{-1}$ which is consistent with the significant increasing of adsorbed water amount in sulfur treated samples. One should then deduce that the carbon-nitrogen network was not changed by the sulfur treatment (id est the formation of heteroaromatic rings is not damaged), which involves that the evolution of crystallinity should be mainly related to "bonded water" loss.

\subsection{Discussion on relations between structure and crystallinity}

On the basis of our XRD, IR, XPS and NMR characterizations and taking into account the elemental analysis, we can, in a first time, propose two schematic models to describe the carbon nitride skeleton of raw-sample.

The first one (called here "Triazine model") is derived from the theoretical hexagonal graphitic $\mathrm{C}_{3} \mathrm{~N}_{4}$ material predicted by Teter and Hemley [7]. The 
overstoichiometry in nitrogen can here be explained by the presence of $\mathrm{C}_{3} \mathrm{~N}_{3}$ voids accompagnied by a protonation of the bridging nitrogen atoms surrounding the void (hydrogen being here provided by the starting reagent) $[16,19]$.

The second model (called here "Heptazine model") is based on the heptazine (tris-triazine) units which are cross-linked by trigonal $\mathrm{N}$ atoms. The as-obtained heptazine-based sheets are structurally related to the hypothetical polymer melon $[14,23,25,29,34-35,37,43]$. In this case hydrogen is bonded to external nitrogen atoms.

Until now, the structure of basal graphitic carbon nitride sheets is still a matter of dispute. Recently, some calculations have predicted that the Heptazine modelbased materials were significantly lower in energy than the Triazine model-based ones [14]. The problem is that usual characterizations such as IR spectroscopy can not help to make any distinctions between both models [45]. In this way, NMR spectra have been widely recorded $[35,37,43,45-46]$ or predicted via ab initio calculations [47]. In the Heptazine-based model, the ${ }^{13} \mathrm{C}$ MAS NMR spectra are expected to present two signal groups. The first one at $164-169 \mathrm{ppm}$ is characteristic for $\mathrm{CN}_{2}\left(\mathrm{NH}_{2}\right)$ carbon atom ; the second one at 155-157 ppm is relative to $\mathrm{CN}_{3}$ groups $[43,45-46]$. As ever mentioned, in the case of an ideal stoichiometric hexagonal graphitic $\mathrm{C}_{3} \mathrm{~N}_{4}$ material, the ${ }^{13} \mathrm{C}$ MAS NMR spectrum is expected to present a single signal around $150 \mathrm{ppm}\left(\mathrm{CN}_{3}\right.$ group). However, the presence of $\mathrm{C}_{3} \mathrm{~N}_{3}$ voids in the material involving a protonation of the bridging nitrogen (Triazine model), a second signal can be expected at 164-167 ppm (as observed in melamine $[36,45])$. Such NMR results on triazine model-materials have been presented by Zhang et al. [16] on a graphitic $\mathrm{C}_{3} \mathrm{~N}_{3}$-deficient 
hydrogenated carbon nitride. One can then observed that NMR experiments, in this way, will not provide a clear distinction between the two models.

Concerning XPS measurements, as previously mentioned, the component at 288 $\mathrm{eV}$ on $\mathrm{C}$ 1s spectrum is currently attributed to $\mathrm{sp}^{2} \mathrm{C}$ involved in triazine rings (as usually seen in melamine for example). To our knowledge, results on materials derived from Heptazine model were only reported by Komatsu and Nakamura [23]. Authors indicate that the binding energy at $287.7 \mathrm{eV}$ on $\mathrm{C} 1 \mathrm{~s}$ spectra is related to carbon in $>\mathrm{C}=\mathrm{N}$-. In their model, carbon is shared between two rings. Their experiment then indicates that it does not appear experimentally possible to distinguish two different binding energies for $\mathrm{sp}^{2} \mathrm{C}$ depending if they are shared between two $\mathrm{C}_{3} \mathrm{~N}_{3}$ cycles (only in Heptazine model) or only involved in one $\mathrm{C}_{3} \mathrm{~N}_{3}$ cycle (in Heptazine and Triazine models).

As a conclusion, on the only basis of XRD, IR, NMR and XPS characterizations, we are not able to rule out neither Triazine model nor Heptazine one. Our previous EELS experiments and calculations on raw-sample were consistent with a Triazine model but no calculations were made for the Heptazine one [48]. However, the behavior of raw-sample in solvothermal conditions could bring some interesting information. In our group, we have treated raw-sample in solvothermal conditions (100 MPa) between 300 and $500^{\circ} \mathrm{C}$ in presence of a chemical species able to release hydrogen when heated (Goglio et al., unpublished results). We then observed since $350^{\circ} \mathrm{C}$ the partial decomposition of raw-sample leading to the simultaneaous formation of well-crystallized melamine (major phase at $350^{\circ} \mathrm{C}$ ) and melem. The relative amount of melem versus melamine was all the more important since temperature was increased. Above $500^{\circ} \mathrm{C}$, a well-crystallized graphitic carbon nitride is observed. Characterizations are actually in progress to 
describe the mechanisms involved during this treatment and the organization of the as-obtained carbon-nitrogen skeleton. However, it is interesting to notice that this experiment consists in fact in a decomposition-condensation mechanism. In our opinion, the existence of melamine at the beginning of the decomposition mechanism unambiguously proves the existence of triazine cycles in the starting material. However, the presence of melem when starting the decomposition can be either reminiscent from the starting carbon nitride skeleton (according to pressure rules, the system decomposes in order to densify the system by minimizing the vacancies in the graphitic plane) or further formed by condensation of melamine when heated (this thermal condensation being well known $[45,47]$ ). As a conclusion, we do not exclude the presence of heptazine units in raw-sample but triazine rings seems to be widely present. A mass spectroscopy study of rawsample could be of relevant interest to get thorough information concerning the nature of the heteroaromatic rings.

To sum up, the characterization of carbon nitride skeleton is particularly complex. The presence of triazines rings can be admitted and the simultaneous existence of heptazine rings can not be excluded at all. This could for example explain disorder observed into the graphitic planes (hkl reflections with (h, k) $\neq(0,0)$ are broad). Whatever, Triazine model can be considered in a schematic approach as a suitable one to describe raw-material, the basic idea being here the existence of voids into the graphitic planes.

Then, in a schematic triazine model, the experimental $\mathrm{C} / \mathrm{N}$ ratio roughly indicates the absence of one sixth of the cycles, the theoretical composition of the carbonnitrogen framework being $\mathrm{C}_{3} \mathrm{~N}_{4.2} \mathrm{H}_{0.6}\left(\mathrm{C}_{15} \mathrm{~N}_{21} \mathrm{H}_{3}\right)$. We attribute the slight excess of hydrogen experimentally observed to the existence of $\mathrm{H}$-rich groups such as $-\mathrm{NH}_{2}$ 
at the edge parts as ever proposed by Kawaguchi and Nozaki [19]. An example of such an hypothetic structure with an ordering of voids is presented on Fig.7.

We have here succeeded to modulate the crystallinity of the starting material as a function of its chemical composition. We have clearly evidenced that adding sulfur during the decomposition induces a loss of crystallinity of the as-obtained materials despite the main features of hydrogenated carbon nitride network are unchanged (the similarities of the IR spectra reveal that the heteroaromatic rings have not been damaged and the compositions of the dried materials are the same). Contrary to adsorbed water molecules which do not influence XRD patterns, the decrease of the amount of trapped bonded water molecules should be correlated to the loss of crystallinity. Considering that interplanar distance does not depend on the amount of $\mathrm{H}_{2} \mathrm{O}_{\text {bond, }}$ one should then think that these molecules are located into the voids rather than between the graphitic sheets, as ever evidenced by Zhang et al. in case of $\mathrm{HCl}$ molecule insertion [16]. These authors successfully elaborated a $\mathrm{C}_{3} \mathrm{~N}_{4}$ graphitic derivative with a $\mathrm{C}_{6} \mathrm{~N}_{9} \mathrm{H}_{3}$ framework (33\% of voids), each void being here occupied by $\mathrm{Cl}^{-}$anion while an equivalent number of bridging nitrogen were protonated to ensure the charge balance. In this case, the crystallinity was excellent and the structure was solved. Nevertheless, as we observe that, in 180-sample and 250-sample, order is damaged both into (disappearance of low angle reflections) and between the planes (broadening of the $\left(\begin{array}{lll}0 & 0 & 2\end{array}\right)$ reflection), it is then likely that the $\mathrm{HOH}$ triangles of $\mathrm{H}_{2} \mathrm{O}_{\text {bond }}$ molecules are not coplanar with graphene planes and influence their stacking order. Our hypothesis is that the presence of these trapped molecules favors the ordering of the triazine rings around the occupied void, hydrogen bonds ensuring a cohesion of the system. Taking into account the detailed formula of three samples (Table I), 
we can notice that in case of raw-sample the amount of $\mathrm{H}_{2} \mathrm{O}_{\text {bond }}$ is maximum and roughly corresponds to a full occupation of the voids, which then logically enhances the crystallinity. On contrary, as seen in 180-sample and 250-sample, the long range order is damaged when $\mathrm{H}_{2} \mathrm{O}_{\text {bond }}$ amount decreases. It is interesting to notice that Zhang et al. have also obtained a highly crystallized material where voids where fully occupied by chlorine atoms [16].

One main consequence concerns these materials stability, water being involved in the early-decomposition mechanism (raw-material is stable until $420^{\circ} \mathrm{C}$ while 180 sample and 250 -sample decompose since about $170^{\circ} \mathrm{C}$ ). While decomposition of 250-sample is continuous and favors the releasing of trapped water molecules, one can observe that no $\mathrm{H}_{2} \mathrm{O}_{\text {bond }}$ is released for raw-sample before the final decomposition. In addition, each decomposition event is associated, whatever the sample, to a water loss. The departure of trapped water molecules is then strongly correlated to the decomposition of the carbon nitride. Moreover bonded water molecules enhance the thermal stability of the material. Concerning the origin of these trapped water molecules, we think that they can be provided either by the highly hygroscopic reagent or by some residual water in the nitrogen flow during thermal decomposition.

\section{Conclusion}

Thermal decomposition of thiosemicarbazide at ambient pressure and temperature up to $600^{\circ} \mathrm{C}$ under nitrogen flow led to the formation of a well-crystallized graphitic carbon nitride. The overstoichiometry in nitrogen was explained with a schematic model involving triazine ring voids associated to a protonation of bridging nitrogen. However, we have shown here that, as previously mentioned in literature, the 
distinction between triazine and tri-s-triazine units is difficult to do experimentally. We think that a thourough study of the thermal decomposition mechanisms, in particular involving pressure parameter, could be a significant help to get information on the nature of the heteroaromatic rings in graphitic carbon nitrides.

A sulfur addition during the decomposition of the organic reagent allowed modulating the amount of bonded water molecules trapped into the voids. We have shown that the crystallinity of the graphitic carbon nitride was strongly dependent on this water amount and was optimized when all voids are occupied. From a general point of view it can be considered that the crystallinity of nitrogenrich graphitic carbon nitrides could be enhanced if $\mathrm{C}_{3} \mathrm{~N}_{3}$ voids are occupied by chemical species containing electronegative elements $\left(\mathrm{O}\right.$ in $\mathrm{H}_{2} \mathrm{O}, \mathrm{Cl}$ in $\mathrm{HCl}$...). It is reasonable to consider that hydrogen bonds occur between this electronegative element and hydrogen linked to the bridging nitrogen atom, which explains the great cohesion in the material. Nevertheless, on the basis of Zhang's works [16], we can not exclude a dissociation of the $\mathrm{H}_{2} \mathrm{O}_{\text {bond }}$ molecules. In this last case, voids should be occupied by $\mathrm{OH}^{-}$anions while a bridging nitrogen could undergo a supplementar protonation inducing an $\mathrm{sp}^{3}$ hybridization.

While the decomposition mechanism of the graphitic carbon nitride is depending on the trapped water molecules amount, the final decomposition temperature remains constant. It is interesting to notice that when all voids are occupied by water, the material is stable until $420^{\circ} \mathrm{C}$ while a continuous decomposition occurs since $170^{\circ} \mathrm{C}$ when voids are partially filled. A further care should be given to understand the decomposition mechanisms in both cases in order to explain the possible role of bonded water molecules. 


\section{Acknowledgments}

This work was partially supported by Centre National de la Recherche Scientifique

(Programme Matériaux Nouveaux - Fonctionnalités Nouvelles). Authors thank Dominique Denux (ICMCB-CNRS) for TGA and MS measurements. 


\section{References}

[1] R. Riedel, Adv. Mater. 6 (1994) 549-560

[2] A.Y. Liu, M.L. Cohen, Science 245 (1989) 841-842

[3] A.Y. Liu, M.L. Cohen, Phys. Rev. B 41 (1990)10727-10734

[4] A.Y. Liu, R.M. Wentzcovitch, Phys. Rev. B 50 (1994) 10362-10365

[5] Y. Guo, W.A. Goddard, Chem. Phys. Lett. 237 (1995) 72-76

[6] J. Martin-Gil, F.J. Martin-Gil, M. Sarikaya, M. Qian, M. José-Yacaman, J. Appl. Phys. 81 (1997) 2555-2559

[7] D.M. Teter, R.J. Hemley, Science 271 (1996) 53-55

[8] M. Côté, M.L. Cohen, Phys. Rev. B 55 (1997) 5684-5688

[9] G. Goglio, D. Foy, G. Demazeau, Mater. Sci. Eng. R 58 (2008) 195-227

[10] S. Muhl, J.M. Mendez, Diamond Relat. Mater. 8 (1999) 1809-1830

[11] L. Vel, G. Demazeau, J. Etourneau, Mater. Sci. Eng. B 10 (1991) 149-164

[12] I. Alves , G. Demazeau, B. Tanguy, F. Weill, Solid State Commun. 109 (1999) 697-701

[13] J. Ortega, O.F. Sankey, Phys. Rev. B 51 (1995) 2624-2627

[14] E. Kroke, M. Schwarz, Coord. Chem. Rev. 248 (2004) 493-532

[15] D.R. Miller, J. Wang, E.G. Gillan. J. Mater. Chem. 12 (2002) 2463-2469

[16] Z. Zhang, K. Leinenweber, M. Bauer, L.A.J. Garvie, P.F. Mc Millan, G.H. Wolf, J. Am. Chem. Soc. 123 (2001) 7788-7796

[17] Y.C. Zhao, D.L. Yu, H.W. Zhou, Y.J. Tian, O. Yanagisawa, J. Mater. Sci. 40 (2005) 2645-2647

[18] C. Li, X. Yang, B. Yang, Y. Yan, Y. Qian, Mater. Chem. Phys. 103 (2007) 427-432

[19] M. Kawaguchi, K. Nozaki, Chem. Mater. 7 (1995) 257-264 
[20] H. Montigaud, B. Tanguy, G. Demazeau, I. Alves, M. Birot, J. Dunogues, Diamond Relat. Mater. 8 (1999) 1707-1710

[21] H.A. Ma, X.P. Jia, L.X. Chen, P.W. Zhu, W.L. Guo, X.B. Guo, Y.D. Wang, S.Q. Li, G.T. Zou, G. Zhang, P. Bex, J. Phys. Condens. Matter 14 (2002) 11269-11273

[22] H. Montigaud, B. Tanguy, G. Demazeau, I. Alves, S. Courjault, J. Mater. Sci. 35 (2000) 2547-2552

[23] T. Komatsu, T. Nakamura, J. Mater. Chem. 11 (2001) 474-478

[24] E.G. Gillan, Chem. Mater. 12 (2000) 3906-3912

[25] T. Komatsu, Macromol. Chem. Phys. 202 (2001) 19-25

[26] G. Goglio, D. Andrault, S. Courjault, G. Demazeau, High Pressure Res. 22 (2002) 535-537

[27] H. Zhao, X. Chen, C. Jia, T. Zhou, X. Qu, J. Jian, Y. Xu, T. Zhou, Mater. Sci. Eng. B 122 (2005) 90-93

[28] Q. Guo, Y. Xie, X. Wang, S. Lv, T. Hou, X. Liu, Chem. Phys. Lett. 380 (2003) 84-87

[29] M. Groenewolt, M. Antonietti, Adv. Mater. 17 (2005) 1789-1792

[30] X.A. Zhao, C.W. Ong, Y.C. Tsang, Y.W. Wong, P.W. Chan, C.L. Choy, Appl. Phys. Lett. 66 (1995) 2652-2654

[31] Q. Luv, C.B. Cao, J.T. Zhang, C. Li, H.S. Zhu, Appl. Phys. A 79 (2004) 633636

[32] A. Andreyev, M. Akaishi, D. Golberg, Diamond Relat. Mater. 11-12 (2002) 1885-1889

[33] H.X. Han, B.J. Feldman, Solid State Commun 65 (1988) 921-923

[34] T. Komatsu, J. Mater. Chem. 11 (2001) 802-805 
[35] B.V. Lotsch, W. Schnick, Chem. Mater. 18 (2006) 1891-1900

[36] B.V. Lostch, W. Schnick, Chem. Eur. J. 13 (2007) 4956-4968

[37] J.R. Holst, E. G. Gillan, J. Am. Chem. Soc. 130 (2008) 7373-7379

[38] G. Goglio, A. Denis, E. Gaudin, C. Labrugère, D. Foy, A. Largeteau, Z Naturforsch. 63 b (2008) 730-738

[39] J.L. Zimmerman, R. Williams, V.N. Khabashesku, J.L. Margrave, Russ. Chem. Bull. Int. Ed. 50 (2001) 2020-2027

[40] Q. Guo, Y. Xie, X. Wang, S. Zhang, T. Hou, S. Lv, Chem. Commun. 1 (2004) 26-7

[41] V.N. Khabashesku, J.L. Zimmerman, J.L. Margrave, Chem. Mater. 12 (2000) $3264-3270$

[42] N. Hellgren, J. Guo, C. Sathe, A. Agui, J. Nordgren, Y. Luo, H. Agren, J.E. Sundgren, Appl. Phys. Lett . 79 (2001) 4348-4350

[43] B.V. Lotsch, M. Döblinger, J. Sehnert, L. Seyfarth, J. Senker, O. Oeckler, W. Schnick, Chem. Eur. J. 13 (2007) 4969-4980

[44] D.R. Lide, Handbook of Chemistry and Physics, CRC Press Boca Raton London New York, Washington DC. 2004-2005; 4:61-87

[45] B. Jürgens, E. Irran, J. Senker, P. Kroll, H. Müller, W. Schnick, J. Am. Chem. Soc. 125 (2003) 10288-10300

[46] N.E.A. El-Gamel, L. Seyfarth, J. Wagler, H. Ehrenberg, M. Schwarz, J. Senker, E. Kroke, Chem. Eur. J. 13 (2007) 1158-1173

[47] J. Sehnert, K. Baerwinkel, J. Senker, J. Phys. Chem. B 111 (2007) 1067110680

[48] P. Moreau, F. Boucher, G. Goglio, D. Foy, V. Mauchamp, G. Ouvrard, Phys. Rev. B 73 (2006) art.195111 
Table

Table I. Chemical composition of the three samples deduced from elemental combustion analysis and thermogravimetric analysis

\begin{tabular}{llll}
\hline Sample & raw-sample 2.4 & 180-sample 13.6 & 250-sample \\
\hline $\mathrm{C} / \mathrm{N} / \mathrm{H} / \mathrm{O} / \mathrm{S}$ at\% & $31.60 / 43.92 / 20.20 / 4.25 / 0$ & $26.93 / 37.45 / 27.11 / 8.50 / 0$ & $26.89 / 37.47 / 27.15 / 8.48 / 0$ \\
$\mathrm{C} / \mathrm{N}$ (molar ratio) & 0.72 & 0.72 & 0.72 \\
$\begin{array}{ll}\text { General formula } \\
\text { a }\end{array}$ & $\mathrm{C}_{3.00} \mathrm{~N}_{4.17} \mathrm{H}_{1.92} \mathrm{O}_{0.40}$ & $\mathrm{C}_{3.00} \mathrm{~N}_{4.17} \mathrm{H}_{3.02} \mathrm{O}_{0.95}$ & $\mathrm{C}_{3.00} \mathrm{~N}_{4.18} \mathrm{H}_{3.03} \mathrm{O}_{0.95}$ \\
$\begin{array}{l}\text { Formula of "dry" } \\
\text { materials + adsorbed } \\
\text { water }\left(\mathrm{H}_{2} \mathrm{O}_{a d s}\right)\end{array}$ & $\begin{array}{l}\mathrm{C}_{3.00} \mathrm{~N}_{4.17} \mathrm{H}_{1.64} \mathrm{O}_{0.26} \\
+0.14 \mathrm{H}_{2} \mathrm{O}_{a d s}\end{array}$ & $\mathrm{C}_{3.00} \mathrm{~N}_{4.17} \mathrm{H}_{1.32} \mathrm{O}_{0.10}$ & $\mathrm{C}_{3.00} \mathrm{~N}_{4.18} \mathrm{H}_{1.33} \mathrm{O}_{0.10}$ \\
$\begin{array}{l}\text { Detailed formula of } \\
\text { "dry" materials }\end{array}$ & $\mathrm{C}_{3.00} \mathrm{~N}_{4.17} \mathrm{H}_{1.12} \bullet 0.26 \mathrm{H}_{2} \mathrm{O}_{\text {bond }}$ & $\mathrm{C}_{3.00} \mathrm{~N}_{4.17} \mathrm{H}_{1.12} \bullet 0.10 \mathrm{H}_{2} \mathrm{O}_{\text {bond }}$ & $\mathrm{C}_{3.00} \mathrm{~N}_{4.17} \mathrm{H}_{1.13} \bullet 0.10 \mathrm{H}_{2} \mathrm{O}_{\text {bond }}$ \\
\hline
\end{tabular}

a The general formula is the raw composition deduced from chemical analysis

b This detailed formula is expressed as "hydrogenated carbon nitride network • bonded $\mathrm{H}_{2} \mathrm{O}$ " 


\section{Figures Captions}

Figure 1. Thermogravimetric analysis of a) raw-sample, b) 180-sample and c) 250-sample. In the inset, thermal $\mathrm{H}_{2} \mathrm{O}$ evolution curves from mass spectrometry measurements on a) raw-sample and c) 250-sample.

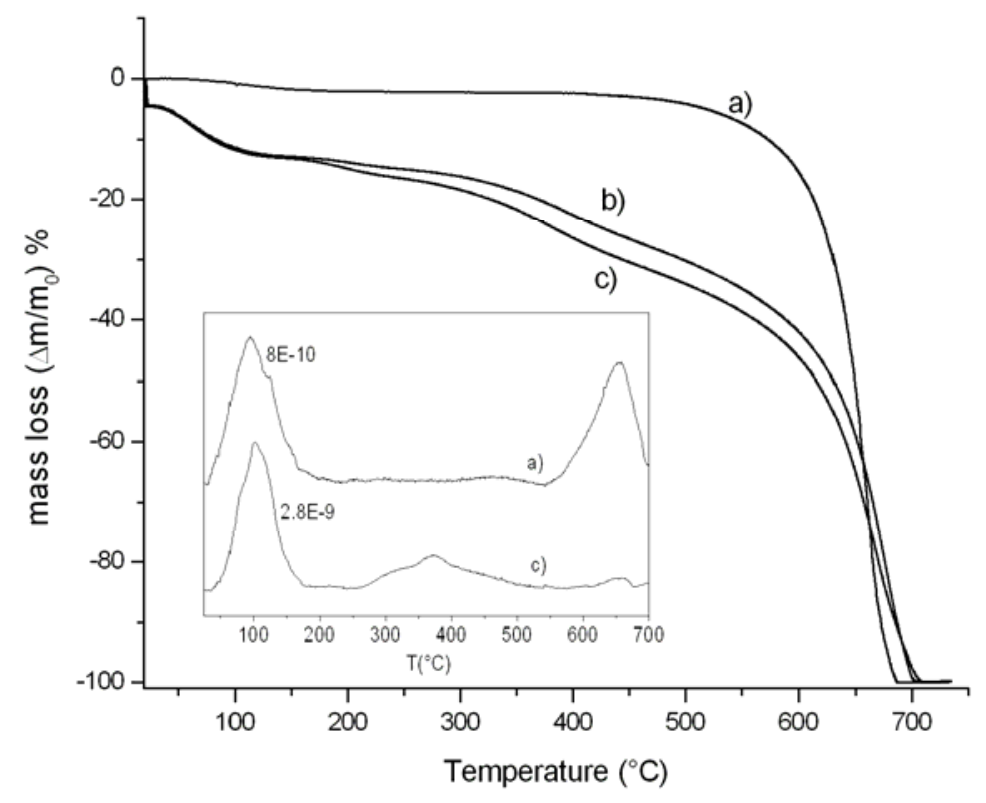

Figure 2. XRD patterns of a) raw-sample, b) 180-sample and c) 250-sample. In this inset, XRD patterns of d) 180-sample and e) dried 180-sample are shown; in this case, to avoid contact with air, the powders were enclosed in a chamber filled by nitrogen with windows transparent for the X-ray beam (mylar foils) 


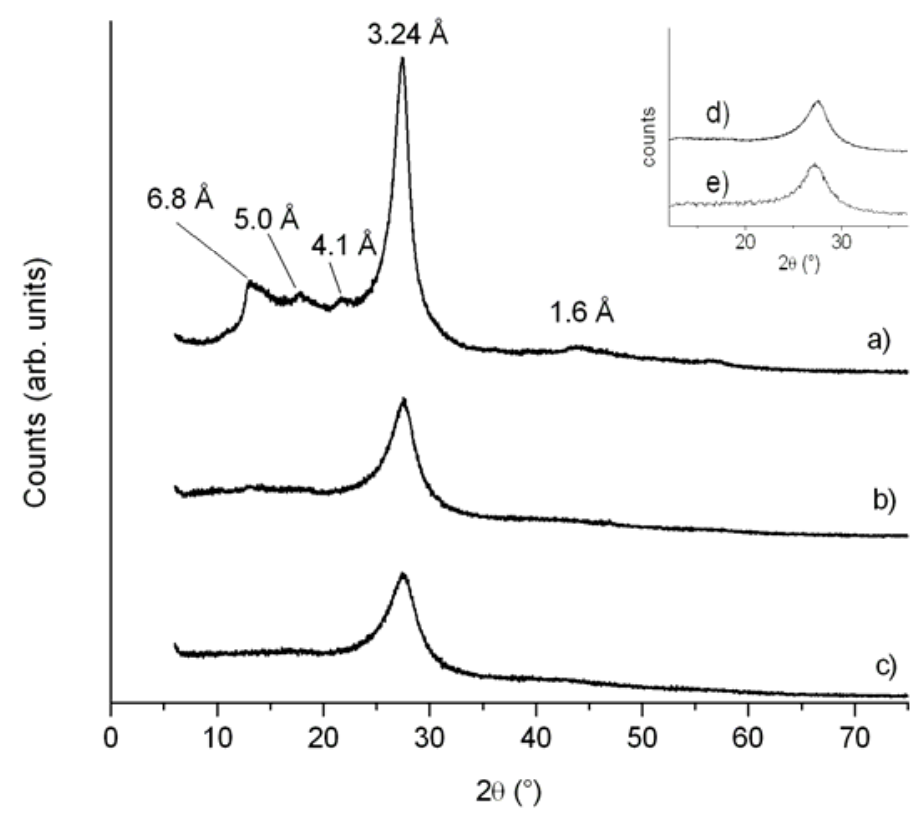

Figure 3. IR spectra of a) raw-sample, b) 180-sample and c) 250-sample

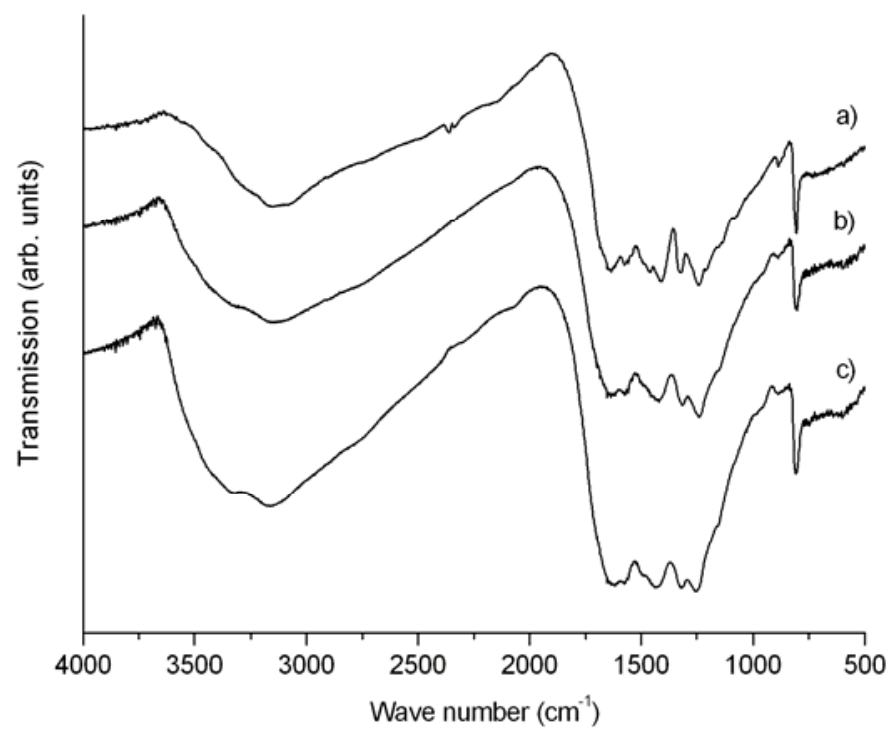


Figure 4. Experimental and fitted XPS spectra of raw-sample a) C1s and b) $\mathrm{N}$ 1s

a)

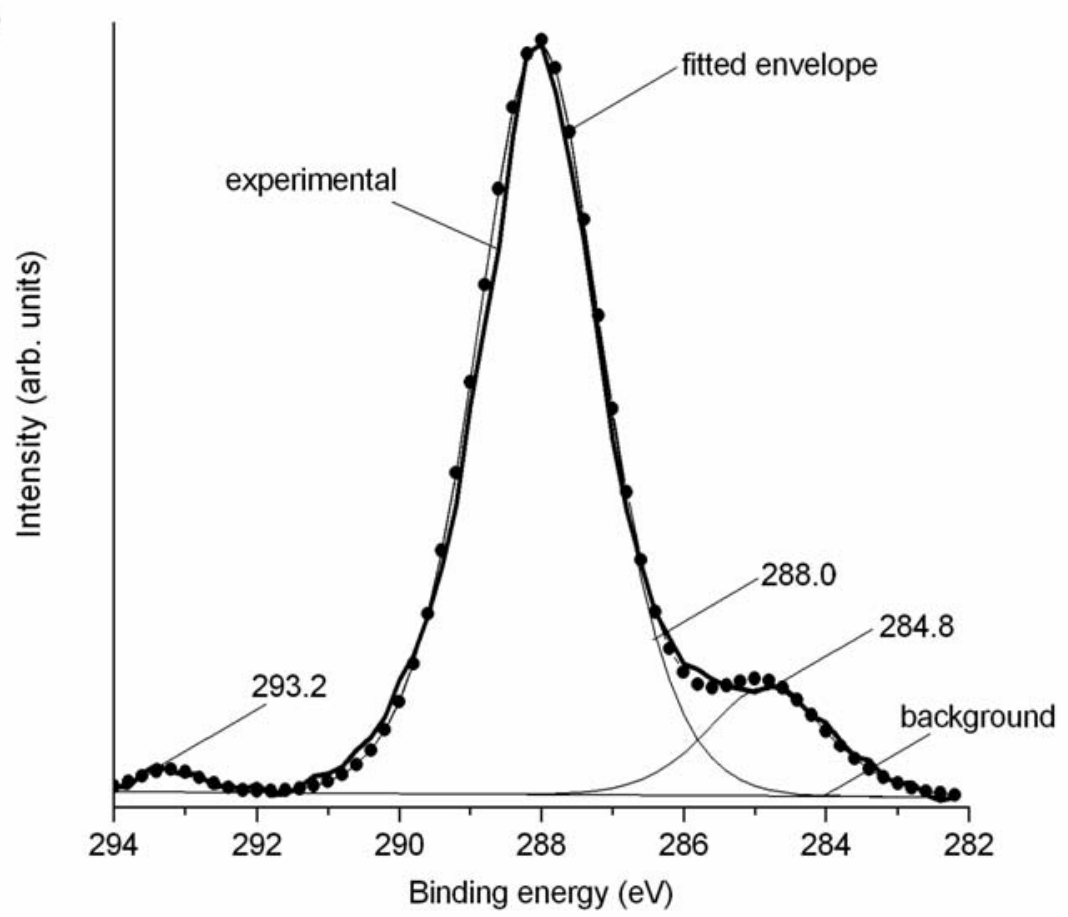

b)

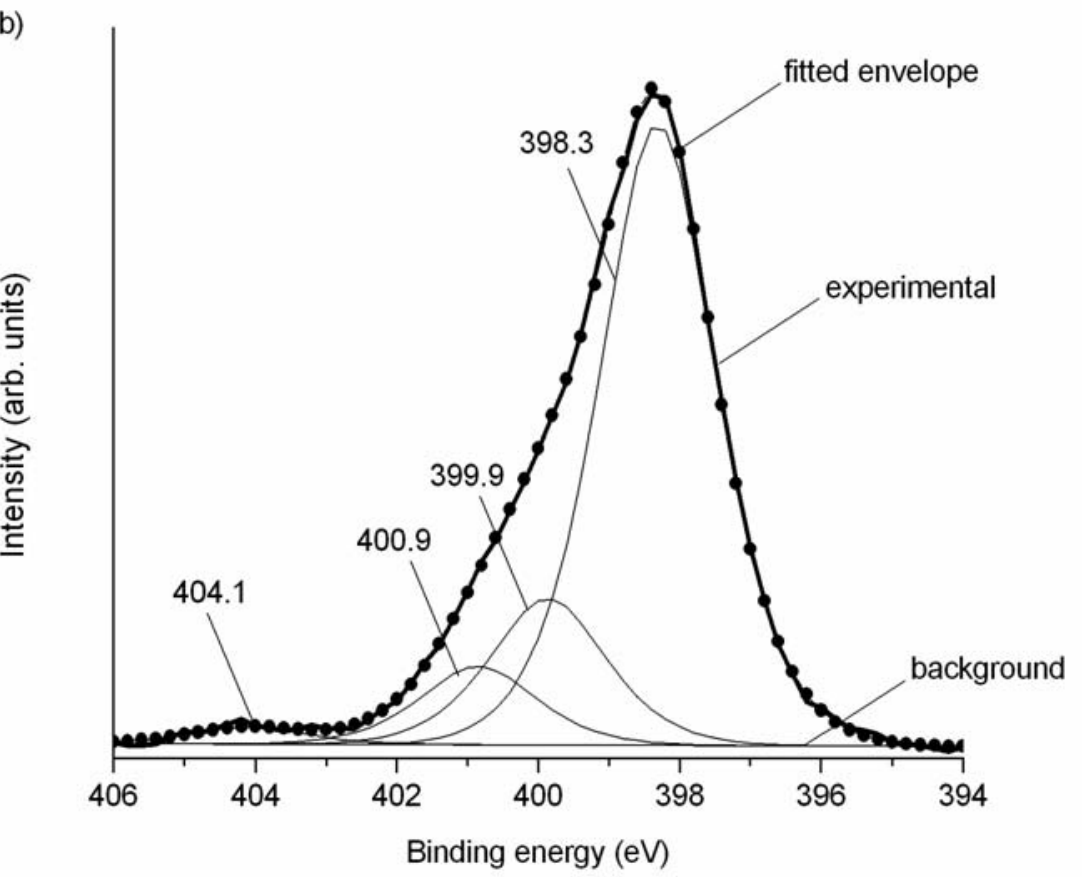


Figure 5. $\quad \mathrm{C}^{13}$ MAS NMR spectrum of raw-sample showing two separated lines at 164 ppm $\left(\mathrm{CN}_{2}\left(\mathrm{NH}_{\mathrm{x}}\right)\right.$ and $157 \mathrm{ppm}\left(\mathrm{CN}_{3}\right)$

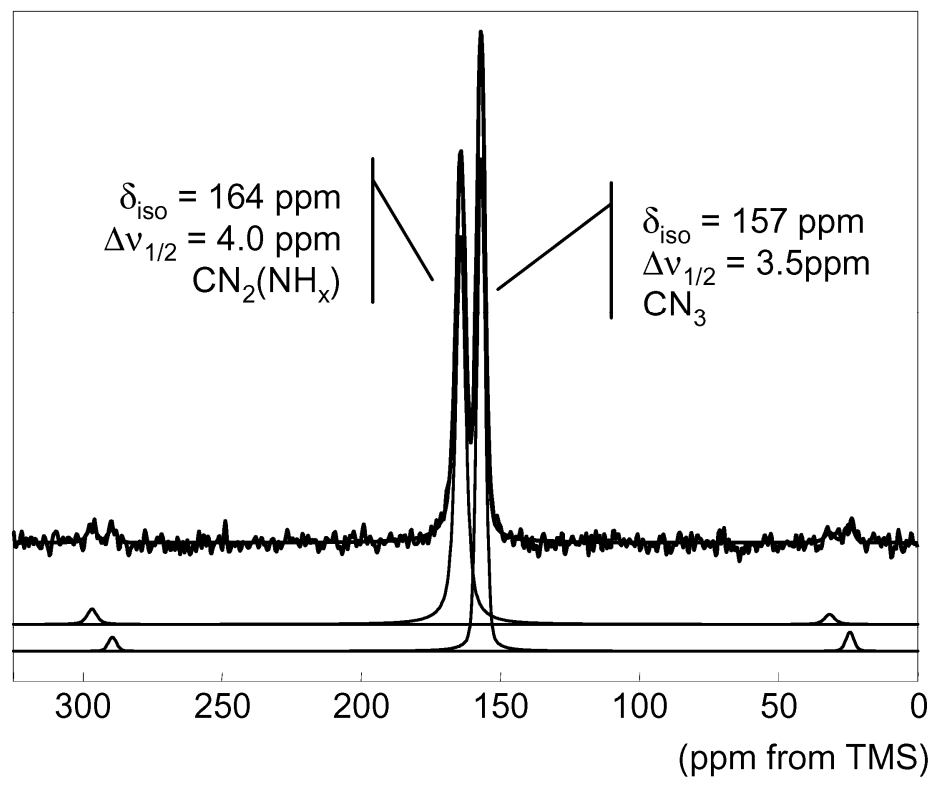

Figure 6. $\quad{ }^{1} \mathrm{H}$ MAS NMR spectrum of raw-sample

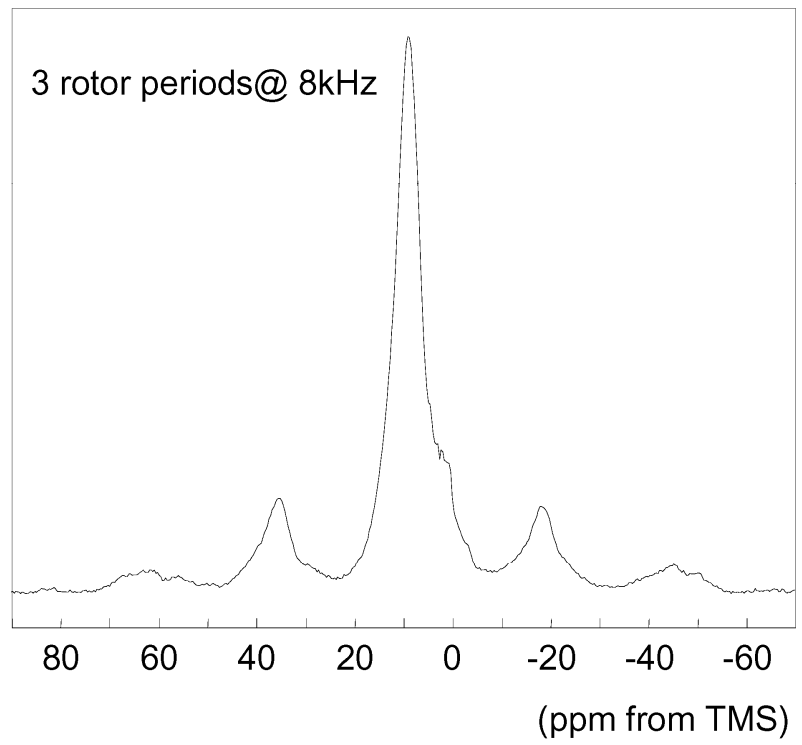


Figure 7. Schematic representation of $\mathrm{C}_{3} \mathrm{~N}_{4.2} \mathrm{H}_{0.6}$ framework with an ordering of voids in a Triazine model

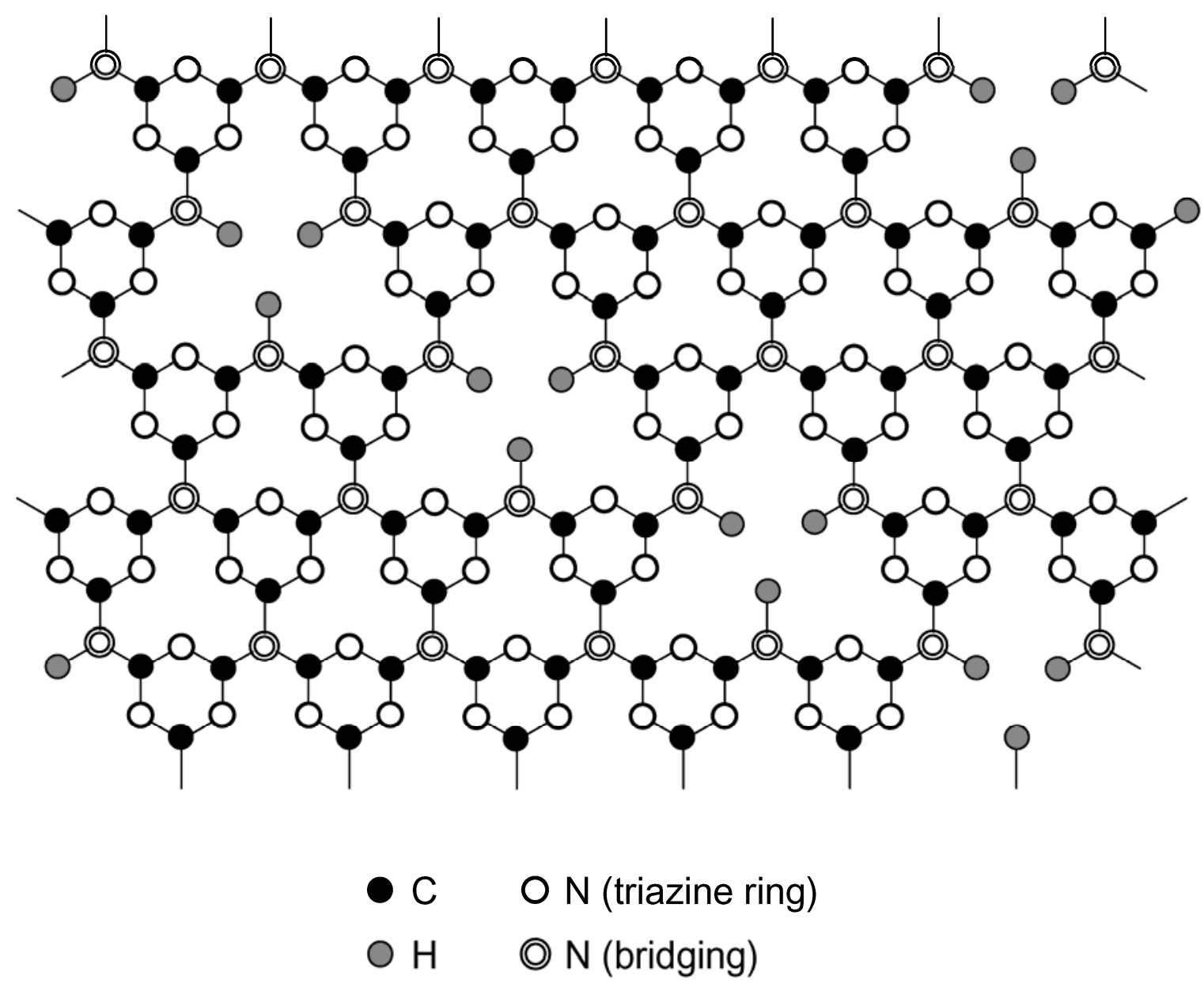

